\title{
STABILIZATION POND SYSTEMS FOR WASTEWATER TREATMENT: FACILITY COSTS AND ENVIRONMENTAL FOOTPRINT ASSESSMENT
}

\author{
GIKAS G.D. ${ }^{1}$ \\ TSIHRINTZIS V.A. ${ }^{2, *}$
}

\author{
${ }^{1}$ Laboratory of Ecological Engineering and Technology \\ Department of Environmental Engineering, School of Engineering \\ Democritus University of Thrace, 67100 Xanthi, Greece \\ ${ }^{2}$ Laboratory of Reclamation Works and Water Resources Management \\ Department of Infrastructure and Rural Development \\ School of Rural and Surveying Engineering \\ National Technical University of Athens, Greece
}

Received: $31 / 10 / 2013$

Accepted: $16 / 02 / 2014$

*to whom all correspondence should be addressed:

Available online: 19/02/2014 e-mail: tsihrin@central.ntua.gr

\begin{abstract}
Natural systems offer an economic solution for the treatment of wastewater from small settlements. This study presents a detailed technical analysis of three stabilization pond systems designed to treat municipal wastewater, varying in capacity from 250 to 1400 population equivalent. Construction costs for the three systems were estimated using standard costing tables for public works for year 2010. The data from the three systems were used to derive empirical equations predicting the required facility surface area and construction cost as function of the design population. For the environmental impact assessment, two construction scenarios were examined: using reinforced concrete and using earthen structures. For the latter case, two options were tested: use of a synthetic geomembrane and use of a compacted clay layer as waterproofing materials. The environmental footprint was calculated for these scenarios applying the Life Cycle Analysis (LCA) methodology. It was concluded that soil structures, and particularly use of clay, had an overall economic and environmental advantage compared to reinforced concrete.
\end{abstract}

Keywords: municipal wastewater treatment, natural treatment systems, stabilization ponds, construction cost, operation cost, Life Cycle Analysis, LCA

\section{Introduction}

Wastewater treatment contributes to the reduction of pollution and contamination of natural waters, and the improvement of aquatic ecosystem health. For the treatment of wastewater in decentralized settlements, the use of natural treatment systems, such as constructed wetlands and stabilization ponds, is a very promising technology (Tsihrintzis and Gikas, 2010; Gikas et al., 2011; Papadopoulos and Tsihrintzis, 2011; Papadopoulos et al., 2011; Papadopoulos et al., 2000; Mara and Pearson, 1987).

Natural systems offer several advantages compared to conventional systems (i.e., activated sludge), which include: a comparable treatment performance; use of renewable energy sources in operation, i.e., lower operation cost; absence of mechanical parts, i.e., less maintenance requirements and longterm, uninterrupted, problem-free operation; no need for qualified operators; and lower costs of construction, operation and maintenance (Tsihrintzis et al., 2007). These systems may also provide indirect benefits, such as aesthetic improvement of the landscape, creation of wildlife habitat, and 
recreational and educational opportunities. Additionally, their effluents can be reused for irrigation. The disadvantage of the natural systems is the requirement of a relatively large area.

For the construction of wastewater treatment plants (WWTPs), various materials are used, such as concrete, steel, polyvinyl chloride (PVC), polyethylene (PE), soil materials, etc. In addition, wastewater treatment is based on several processes where there is need of chemicals, electricity, air supply, etc.; treatment byproducts are also produced, such as sewage sludge, methane, carbon dioxide, etc. The use and production of these materials and substances have a certain, low or high, environmental impact.

In the literature, there are several examples where life cycle analysis (LCA) is used in assessing the environmental impact of various activities, operations and structures related to municipal wastewater treatment (Renou et al., 2008). Examples include, among others: conventional WWTPs (Emmerson et al., 1995); an urban wetland park (Duan et al., 2011); small scale WWTPs (Dixon et al., 2003). Machado et al. (2006) used the LCA methodology to study and compare the environmental impacts of three small scale WWTPs, i.e., a constructed wetland system, a slow-rate filtration system, and a conventional activated sludge system. Among the three, the constructed wetland system showed lower environmental impact. The same software was used by Fuchs et al. (2011) to compare the environmental impact of vertical and horizontal subsurface flow constructed wetlands.

In this paper, we present construction costs of stabilization ponds (anaerobic, facultative, maturation) based on real data from constructed facilities in northern Greece. In addition, the LCA methodology is used in one of these facilities to compare the environmental footprint of various materials and propose environmentally friendly stabilization pond construction methods.

\section{Materials And Methods}

\subsection{Facility description}

To analyze stabilization pond construction cost, data were used from three such facilities, located in the prefecture of Kastoria in northern Greece. These facilities were designed by the National Agricultural Research Foundation (NAGREF), Department of Agricultural Development, in Greece, to serve the residents of the villages Komninades, Kranochori and Nestorio. The facility in Komninades was designed for a 250 population equivalent (p.e.). It comprises in series a screen, a covered anaerobic pond (AP), a facultative pond (FP), a maturation pond (MP), a reservoir (R) and a chlorination tank (CT). The hydraulic retention times (HRT) in the AP, FP, MP and R are 3.4, 24.7, 13.5 and 21.7 days, respectively. The removal of organic loading is mainly achieved in the stabilization ponds, and therefore, the existence of the reservoir is not necessary for wastewater treatment but for water storage for reuse mostly in irrigation.

Figure 1 presents the system in Kranochori (400 p.e.) which comprises in series: a screen, and AP, FP, MP and CT. Figure 2 presents the system in Nestorio (1400 p.e.) which comprises in series: a screen, and AP, FP, two MP, R and CT. The geometric characteristics of the three facilities are presented in detail in Table 1. Area requirements were computed based on volumetric and surface organic loading rates (Mara, 2006).

The anaerobic pond in all systems is made of reinforced concrete. All the other ponds (facultative and maturation) are earthen structures, covered with impermeable $1 \mathrm{~mm}$ thick high density polyethylene (HDPE) geomembrane. 


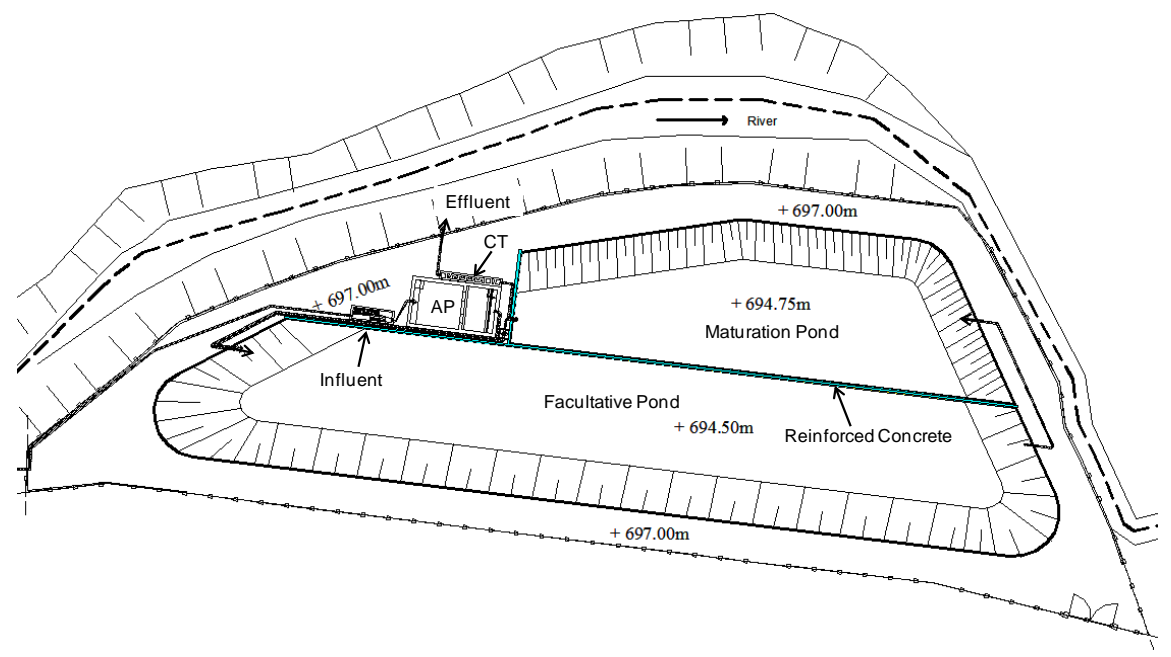

Figure 1. Facility layout in Kranochori village

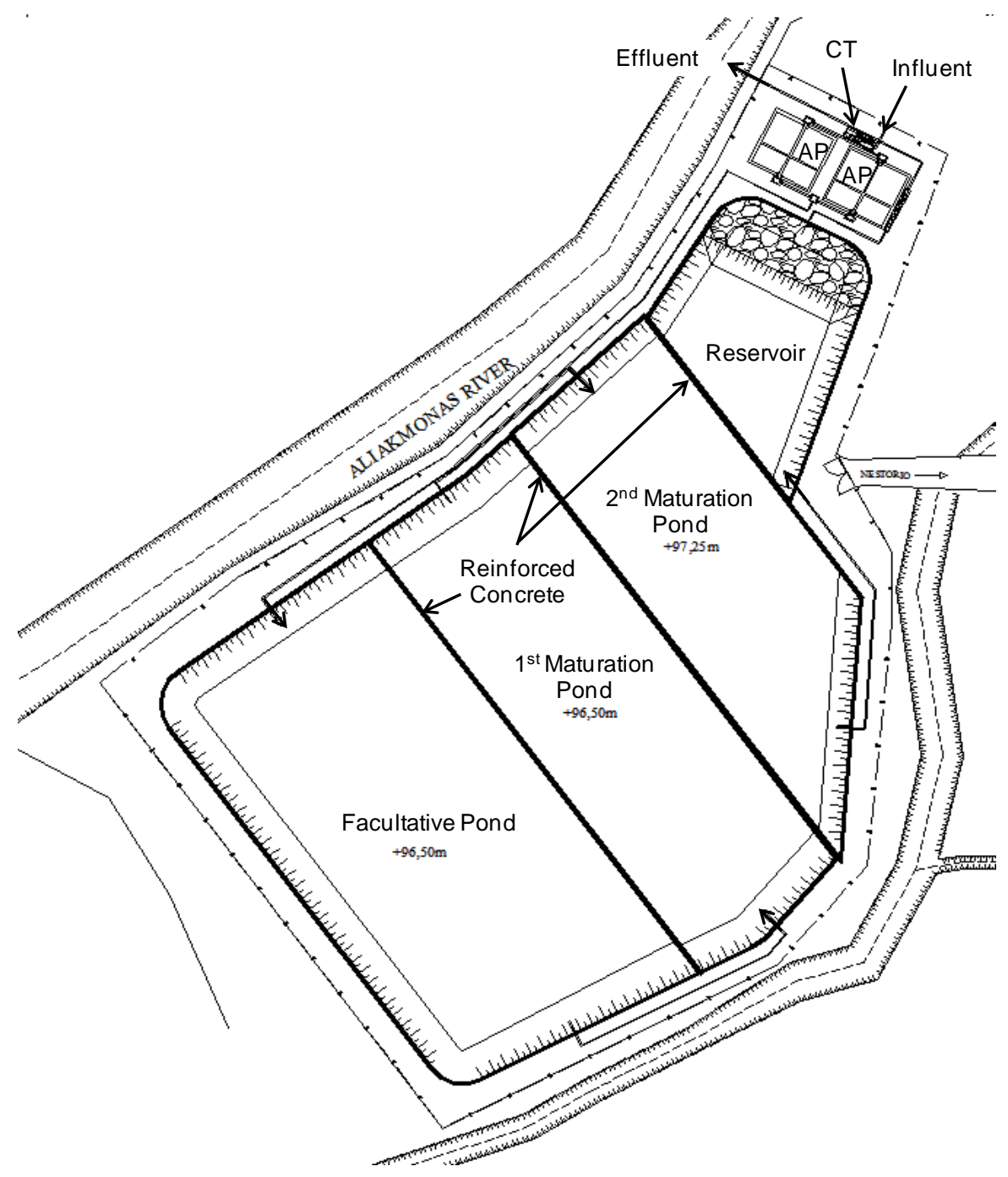

Figure 2. Facility layout in Nestorio village 
In all systems, between the facultative and maturation pond there is a separating wall made of reinforced concrete (Figures 1, 2). All systems also comprise miscellaneous other works, e.g., fence, warehouse and internal access roads. As mentioned, the systems in Komninades and Nestorio contain at the end a reservoir, where the treated wastewater effluent is collected for storage and reuse in various uses (e.g., irrigation, fire combating, etc.). The capacities of the reservoirs are $813 \mathrm{~m}^{3}$ and $870 \mathrm{~m}^{3}$ for Komninades and Nestorio, respectively. Since the reservoirs are not necessary for wastewater treatment, and in order to have comparable results for all systems, the reservoirs were not taken into account in construction cost calculation, which is a main difference from the study by Gikas et al. (2013).

Table 1. Main characteristics of the three studied systems

\begin{tabular}{lccc}
\hline & Komninades & Kranochori & Nestorio \\
\hline Population equivalent & 250 & 400 & 1400 \\
\hline Total area $\left(\mathrm{m}^{2}\right)$ & 2460 & 3900 & 10000 \\
\hline Area / p.e. $\left(\mathrm{m}^{2} /\right.$ p.e. $)$ & 9.84 & 9.75 & 7.14 \\
\hline Active treatment area $\left(\mathrm{m}^{2}\right)$ & 1093 & 2500 & 7020 \\
\hline Active area $/$ p.e. $\left(\mathrm{m}^{2} /\right.$ p.e. $)$ & 4.37 & 6.25 & 5.01 \\
\hline Flow rate $\left(\mathrm{m}^{3} \mathrm{~d}^{-1}\right)$ & 37.5 & 80.0 & 280.0 \\
\hline Area and volume of stabilization ponds & $40 \mathrm{~m}^{2}, 126 \mathrm{~m}^{3}$ & $55 \mathrm{~m}^{2}, 200 \mathrm{~m}^{3}$ & $90 \mathrm{~m}^{2}, 650 \mathrm{~m}^{3}$ \\
\hline \hline Anaerobic Pond & $617 \mathrm{~m}^{2}, 928 \mathrm{~m}^{3}$ & $1630 \mathrm{~m}^{2}, 2560 \mathrm{~m}^{3}$ & $3090 \mathrm{~m}^{2}, 5600 \mathrm{~m}^{3}$ \\
\hline Facultative Pond & $436 \mathrm{~m}^{2}, 508 \mathrm{~m}^{3}$ & $815 \mathrm{~m}^{2}, 1185 \mathrm{~m}^{3}$ & $2110 \mathrm{~m}^{2}, 4095 \mathrm{~m}^{3}$ \\
\hline $1^{\text {st }}$ Maturation Pond & - & - & $1730 \mathrm{~m}^{2}, 2110 \mathrm{~m}^{3}$ \\
\hline $2^{\text {nd }}$ Maturation Pond & 41.6 & 49.3 & 44.4 \\
\hline Total HRT $(\mathrm{d})$ & & & \\
\hline
\end{tabular}

\subsection{Application of LCA to wastewater treatment systems}

Life-cycle assessment (LCA) is a technique used to assess environmental impacts associated with all the stages of the life of a product or structure. This assessment spans from the extraction of the raw materials through the processing of the materials, the manufacturing of the product or the construction of the structure, the distribution, use, repair and maintenance, and the final disposal or recycling of the product or structure (ISO 14040, 1997; Dixon et al., 2003). LCA can be used in assessing the environmental impact of various activities, operations and structures related to municipal wastewater treatment; furthermore, it can be used to evaluate different construction options, techniques or materials (Dixon et al., 2003; Fuchs et al., 2011).

Table 2. Impact categories in Eco-Indicator 99 method (Goedkoop et al., 2008)

\begin{tabular}{ll}
\hline Endpoints grouping & Impact indicator categories \\
\hline Resources & Depletion of fossil fuel \\
& Depletion of minerals \\
\hline Ecosystem quality & Land use \\
& Acidification/eutrophication \\
& Ecotoxicity \\
\hline Human health & Climate change \\
& Ozone layer depletion \\
& Carcinogenic substances \\
& Respiratory effects (organic) \\
& Respiratory effects (inorganic) \\
& lonizing radiation \\
\hline
\end{tabular}


For the LCA, SimaPro software was used (Goedkoop et al., 2008), applying the method Eco-Indicator 99 (ISO 14040, 1997). In this method, the impacts on the environment are divided into eleven categories, grouped into three main areas of endpoints, i.e., resources, ecosystem quality and human health (Table 2).

For the application of the LCA, the following assumptions were made: (a) Each tested system is a set of products and processes divided into subsystems; (b) The transfer of materials used in construction is made using medium and large trucks traveling a distance of $10 \mathrm{~km}$; (c) The time horizon of operation of the system was considered to be 20 years.

\section{Results and Discussion}

\subsection{Economic evaluation}

The construction costs were estimated based on standard costing tables for public works provided by the Hellenic Department of Public Works for year 2010 (General Secretariat of Public Works). These tables are used for costing all public work construction activities in Greece. Empirical cost equations of the form $y=a x^{b}$, where $a$ and $b$ are calculated coefficients, were used to express construction cost and land requirements relative to design population (Xian-wen, 1995). This form of equation was found better compared to a polynomial form used by Gikas et al. (2013). The construction cost of the various parts of the systems, the total construction cost and the operation cost are presented in Table 3 . The inlet works include the screen, the inlet vault and the PVC pipes, and the outlet works include the outlet vault and the chlorination tank. The miscellaneous other works (MOW) includes the fence, warehouse and internal access roads.

The operation cost comprises the following: (1) cost of chlorination and dechlorination (chemicals and electric energy for pump operation); and facility operator wages (one person working part-time, i.e., 2, 3 or 5 hours/day for the Komninades, Kranochori and Nestorio facilities, respectively) for the operation and maintenance of the facility.

Table 3. Construction and operation cost in Euro $(€)$ of the three studied systems

\begin{tabular}{lccc}
\hline & Komninades & Kranochori & Nestorio \\
\hline Inlet works & 3,511 & 3,080 & 3,487 \\
Anaerobic pond & 27,949 & 40,662 & 103,365 \\
Facultative pond & 21,442 & 39,715 & 59,715 \\
Maturation pond & 19,362 & 24,684 & 80,682 \\
Outlet works & 4,294 & 5,384 & 5,513 \\
Miscellaneous other works & 11,219 & 14,715 & 17,381 \\
Construction cost (€) & 87,777 & 128,239 & 270,143 \\
Construction cost /p.e. (€/p.e.) & 351 & 321 & 193 \\
Total cost ( $€)^{\text {a }}$ & 127,399 & 186,126 & 392,086 \\
Total cost / p.e. (€/p.e.) & 510 & 465 & 280 \\
Annual operation cost (€/year) & 5,785 & 8,627 & 15,129 \\
Operation cost / p.e. (€/p.e./year) & 23.1 & 21.6 & 10.8 \\
\hline a It includes professional engineer's fees (18\%) and VAT (23\%) & & \\
\hline
\end{tabular}

Figure 3 shows the relationship of the total construction cost of the stabilization pond system relative to the design population (p.e.). The main disadvantage of natural wastewater treatment systems is the requirement of a relatively large area. Figure 4 shows the total area $\left(\mathrm{m}^{2}\right)$ needed for each system in 
relation to the design population. One can observe scale economy in both cases, as the total cost and the total area initially increase rapidly, and then, they level off as the system capacity increases. Figures 3 and 4 also present relevant equations fitted through regression analysis for both cases. In both cases, the determination coefficient $R^{2}$ is excellent (greater than 0.99). These equations, although derived from a small number of units, enable estimates of construction cost and surface area requirement for similar systems as function of design population. Mburu et al. (2013) reported that the construction cost of a wastewater stabilization pond system for 2700 p.e. in Juja town, Kenya was $€ 369,600$. The equation of Figure 3 would estimate it at $€ 414,000$. This $12 \%$ overestimate is considered minor if one takes into account the different geographic locations of the facilities. Therefore, there is a first indication that these equations are reliable. The use of additional systems in the future for testing these equations will provide additional certainty in the estimates.

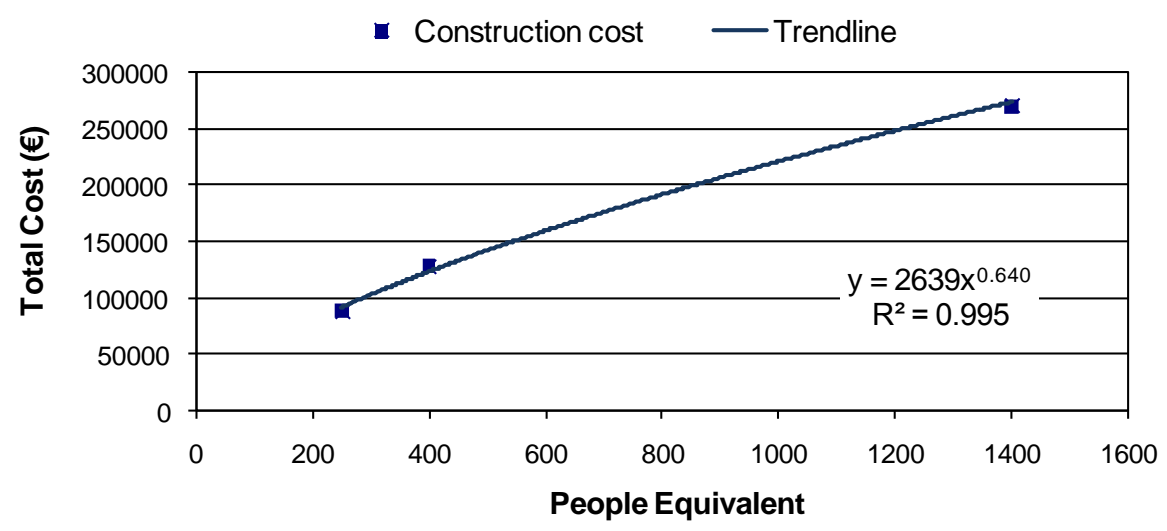

Figure 3. Total construction cost as function of design population

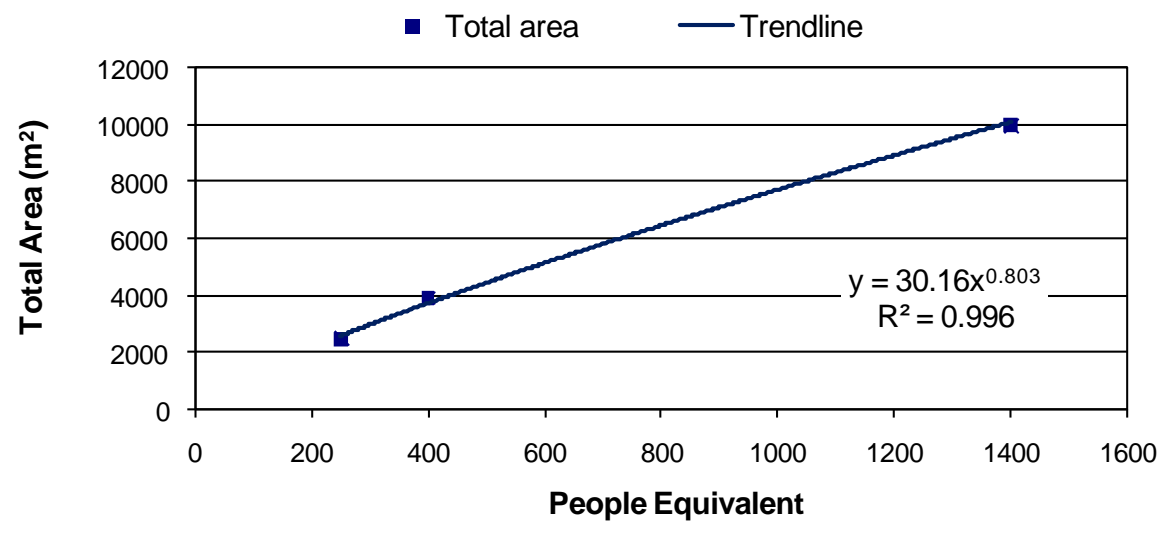

Figure 4. Facility surface area as function of design population

Figure 5 presents the percent breakdown of construction costs (Table 3 ) in the various parts of the facility. As the system capacity increases, one can observe a reduction in the percent cost for inlet and outlet works and for the other works. On the contrary, the percent cost of the anaerobic pond increases with increasing design population. The reason for this is that increased volumes of reinforced concrete are used, which is an expensive material. The land area per p.e. $\left(\mathrm{m}^{2} /\right.$ p.e.) of facultative ponds is $2.5,4.1$ and 2.2 and of maturation ponds is 1.7, 2.0 and 2.7 for Komninades, Kranochori and Nestorio facilities, respectively. This is probably the reason that in facultative and maturation ponds the trend of the percent cost is not clear. The contribution of the anaerobic pond is in all three systems the largest in the total construction cost, i.e., about 32\% for Komninades and Kranochori and 38\% for Nestorio facilities. An alternative method of construction was also explored for the anaerobic pond, aiming to reduce the total construction cost of the facility: it was redesigned as an open earthen pond. In this case, two 
scenarios were examined for waterproofing the earthen anaerobic pond, i.e.: (a) using a HDPE geomembrane (thickness $1.0 \mathrm{~mm}$ ), similar to the one used in the following facultative and maturation ponds; and (b) using a layer of compacted clay (thickness $0.3 \mathrm{~m}$ ).

Figure 6 shows a comparison of the cost of alternative construction of anaerobic pond relative to the design population. An exponential regression line is shown to describe well the construction cost of the anaerobic pond relative to the design population for the three cases examined, i.e., using a reinforced concrete tank, using a HDPE geomembrane and using a compacted clay layer. In all cases, the determination coefficient $R^{2}$ is excellent (greater than 0.99). From the graph, it appears that the earthen pond with clay layer presents the lower cost compared to the other two cases, while the most expensive alternative is that of the reinforced concrete tank.

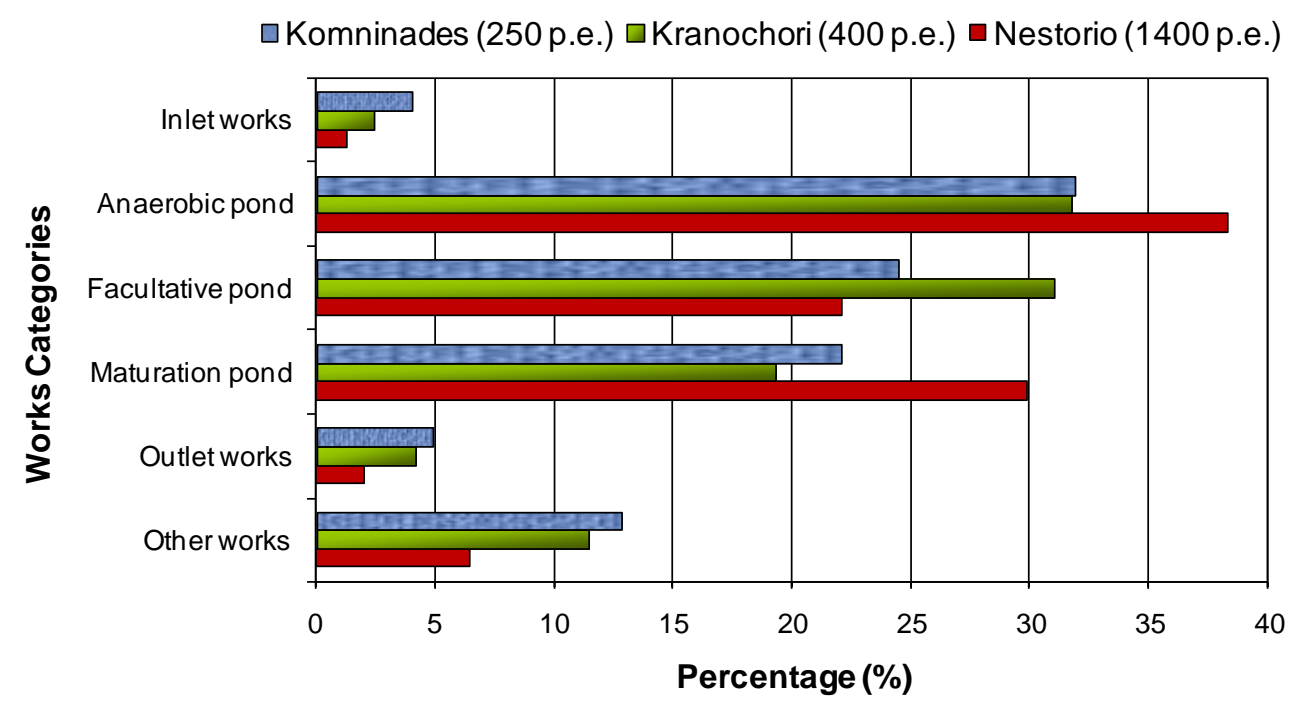

Figure 5. Percent allocation of total construction cost

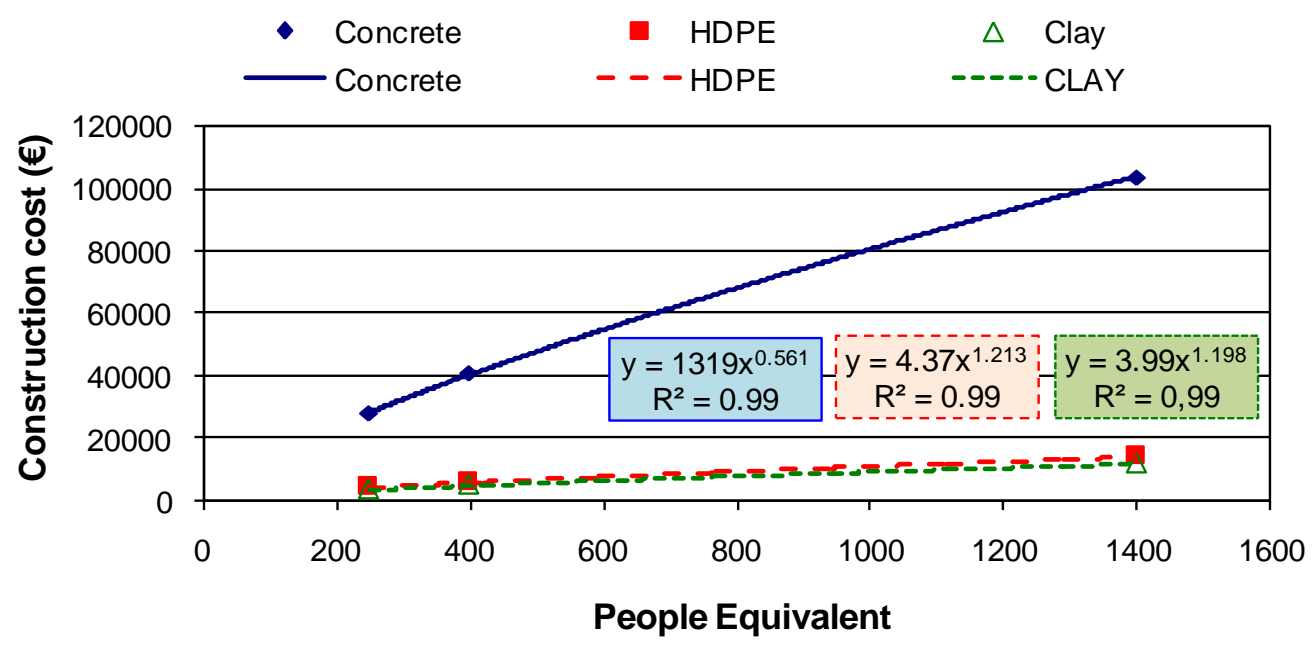

Figure 6. Construction cost of various alternative materials for the anaerobic pond as function of design population

\subsection{Environmental footprint evaluation}

The LCA methodology was applied to the Komninades facility. Figure 7 shows the flow diagram for the construction phase of the facility, illustrating the processes and materials with the largest environmental 
burden. The environmental profile of the facility is determined mainly (36.8\%) by the construction of the anaerobic pond, because of the concrete used and the required steel reinforcement. The facultative pond and the maturation ponds have also a significant participation in the environmental footprint (27.5\%, and $30.1 \%$, respectively); this fact is mainly attributed to the use of the HDPE geomembrane and to the use of concrete for the wall between the ponds (Figures 1, 2,7). Regarding the environmental impacts listed in Table 2, the LCA showed that the anaerobic pond, as designed, has the greatest participation in the impact related to depletion of resources and burden of respiratory effects.

We also examined the environmental footprint for the alternative methods of construction of the anaerobic pond, i.e., constructing an earthen pond covered with either a $1 \mathrm{~mm}$ thick HDPE geomembrane or $30 \mathrm{~cm}$ thick compacted clay layer, and compared it with the reinforced concrete tank. Figure 8 presents a comparison of the three types of anaerobic pond per impact category of the EcoIndicator 99 method. The reinforced concrete anaerobic pond has the highest environmental impact in relation to the earthen alternatives in almost all impact categories. This is mainly due to the use of significant quantities of concrete and steel for the construction. The category in which the earthen tanks present a worse performance than that of concrete is the ozone layer, something attributed to the use of HDPE geomembrane for waterproofing.

Figure 9 presents the total environmental impact for the three main impact categories (Table 2), as a result of the construction and operation of the facility under three different scenarios: (a) as originally designed (LCA1), i.e., reinforced concrete for anaerobic pond, earthen with $1 \mathrm{~mm}$ thick HDPE geomembrane for other ponds; (b) all ponds are earthen with $1 \mathrm{~mm}$ thick HDPE geomembrane (LCA2); and (c) all ponds are earthen with $30 \mathrm{~cm}$ compacted clay layer (LCA3). For the environmental impact on the operational phase of the facility (valid for all scenarios) the following were considered: the energy required for facility operation, and daily travel of one employee to check the facility (the assumption was made that this person travels $2 \mathrm{~km}$ each day by car). Greater environmental impact was computed for the LCA1 scenario because of the use of reinforced concrete in the anaerobic pond. The smallest impact was for the LCA3 scenario where the HDPE geomembrane was replaced by the clay layer. The assumed 20-year operation of the facility has very little environmental impact $(0.34 \mathrm{kPt}$ where $1 \mathrm{kPt}$ is the annual environmental load of the mean European inhabitant) compared to the construction stage (3.85, 2.09 and $1.54 \mathrm{kPt}$ for scenarios LCA1, LCA2 and LCA3, respectively). This is because the facility was designed so that the movement of wastewater from one stage of the facility to the other occurs by gravity. Therefore, it was not necessary to install energy-consuming pumps for wastewater lifting.

\section{Conclusions}

Construction cost and required surface area is presented for stabilization pond wastewater treatment systems as function of design population. LCA is shown to be a useful tool for assessing the environmental footprint of stabilization pond facilities. A comparison of using alternative construction materials highlights the improvements achieved if the anaerobic reinforced concrete tank is replaced by an earthen one (waterproofed with a HDPE geomembrane or compacted clay layer). Between the two, the system of earthen ponds waterproofed with a compacted clay layer was found more environmentally friendly. 


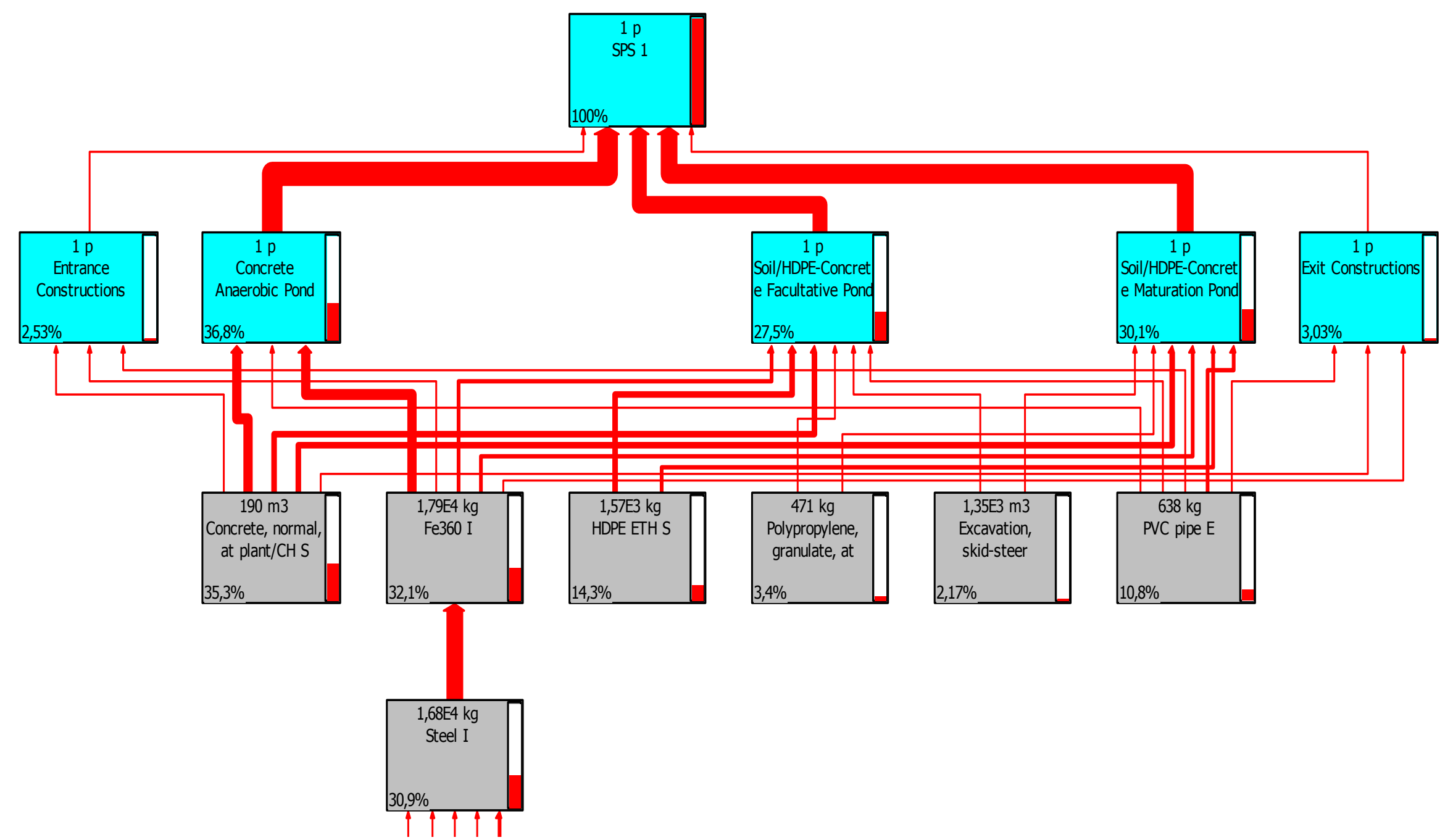

Figure 7. Processes and materials in the environmental footprint of the Komninades stabilization pond system 


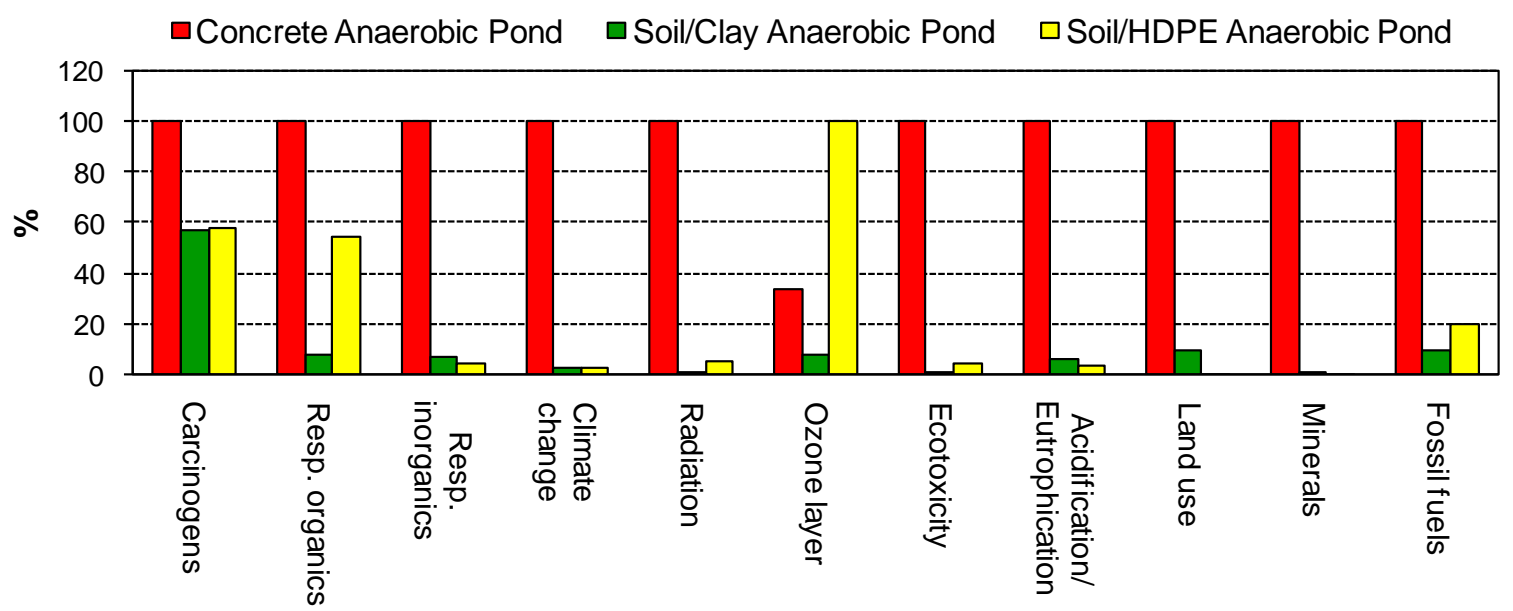

Figure 8. Comparative evaluation of the alternative methods of construction of the anaerobic pond

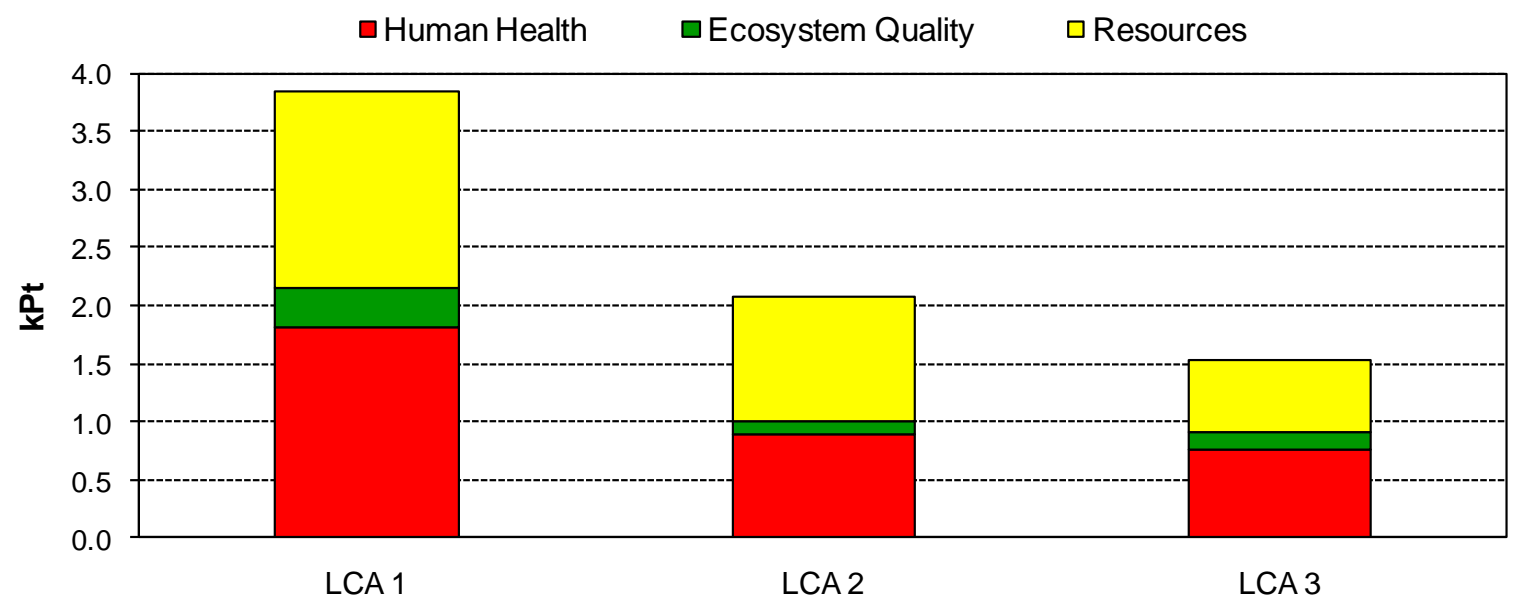

Figure 9. Overall environmental impact of three alternative construction and operation scenarios of the Komninades stabilization pond facility.

\section{ACKNOWLEDGEMENTS}

Dr. F. Papadopoulos from the National Agricultural Research Foundation (NAGREF) provided design data and plans of the three stabilization pond systems. His help is greatly appreciated.

\section{REFERENCES}

Dixon A. Mathew S. and Burkitt T. (2003), Assessing the environmental impact of two options for small-scale wastewater treatment: comparing a reedbed and an aerated biological filter using a life cycle approach, Ecological Engineering, 20(4), 297-308.

Duan N., Liu X.D., Dai J., Lin C., Xia X.H., Gao R.Y., Wang Y., Chen S.Q., Yang J. and QI J. (2011), Evaluating the environmental impacts of an urban wetland park based on energy accounting and life cycle assessment: A case study in Beijing, Ecological Modelling, 222, 351-359.

Emmerson R.H.C., Morse G.K., Lester J.N. and Edge D.R. (1995), Life-cycle analysis of small scale sewage treatment processes, Journal of the Institution of Water \& Environmental Management, 9(3), 317-325. 
Fuchs V.J., Mihelcic J.R. and Gierke J.S. (2011), Life cycle assessment of vertical and horizontal flow constructed wetlands for wastewater treatment considering nitrogen and carbon greenhouse gas emissions, Water Resources, 45, 2073-2081.

General Secretariat of Public Works. Costing tables for public works. http://www.ggde.gr/index.php?option=com docman\&task=cat view\&gid=40\&ltemid=188.

Gikas G.D., Tsihrintzis V.A. and Akratos C.S. (2011), Performance and modeling of a vertical flow constructed wetland - maturation pond system, Journal of Environmental Science and Health, Part A, 46, 692-708.

Gikas G.D., Tsihrintzis V.A. and Papachristos C.G. (2013), Economic and environmental evaluation of stabilization pond systems for wastewater treatment, Proceeding of $13^{\text {th }}$ International Conference on Environmental Science and Technology, CEST2013, Athens, Greece, 5-7 September 2013 (http://cest2013.gnest.org), Paper \# 654.

Goedkoop M., Schryver A. and Oele M. (2008), Introduction to LCA with SimaPro 7, Product Ecology Consultants, the Netherlands.

ISO 14040 (1997), Environmental Management - Life Cycle Assessment - General Principles and Framework, International Organization for Standardization, Geneva, Switzerland.

Machado A.P., Urbano L., Brito A.G., Janknecht P., Salas J.J. and Nogueira R. (2007) Life cycle assessment of wastewater treatment options for small and decentralized communities, Water Science and Technology, 56(3), 15-22.

Mara D.D. and Pearson H.W. (1987), Waste Stabilization Ponds - Design Manual for Mediterranean Europe, World Health Organization (WHO), Regional Office for Europe.

Mara D.D. (2006), Constructed wetlands and waste stabilization ponds for small rural communities in the United Kingdom: a comparison of land area requirements, performance and costs, Environmental Technology, 27(7), 753-757.

Mburu N., Tebitendwa S., van Bruggen J., Rousseau D.P.L. and Lens P. (2013), Performance comparison and economics analysis of waste stabilization ponds and horizontal subsurface flow constructed wetlands treating domestic wastewater: A case study of the Juja sewage treatment works, Journal of Environmental Management, 128, 220-225.

Papadopoulos A., Papadopoulos F., Parisopoulos G. and Karteris A., (2000), Temperature and physicochemical parameters in an anaerobic stabilization pond, Proceedings of 5th International Conference on Environmental Pollution, Thessaloniki, Greece, pp. 249-256.

Papadopoulos F.H. and Tsihrintzis V.A. (2011), Assessment of a full-scale duckweed pond system for septage treatment, Environmental Technology, 32(7), 795-804.

Papadopoulos F.H., Tsihrintzis V.A. and Zdragas A.G (2011), Removal of faecal bacteria from septage by treating it in a full-scale duckweed-covered pond System, Journal of Environmental Management, 92(12), 3130-3135.

Renou S., Thomas J.S., Aoustin E. and Pons M.N. (2008), Influence of impact assessment methods in wastewater treatment LCA, Journal of Cleaner Production, 16(10), 1098.

Tsihrintzis V.A., Akratos C.S., Gikas G.D., Karamouzis D. and Angelakis A.N. (2007), Performance and cost comparison of a FWS and a VSF constructed wetland systems, Environmental Technology, 28(6), 621-628.

Tsihrintzis V.A. and Gikas G.D. (2010), Constructed wetlands for wastewater and activated sludge treatment in North Greece: A review, Water Science and Technology, 61(10), 2653-2672.

Xian-wen L. (1995), Technical economic analysis of stabilization ponds, Water Science and Technology 31(12), 103110. 